\title{
NIETZSCHE E O TRANS-HUMANISMO: EM TORNO DA QUESTÃO DA AUTOSSUPERAÇÃO DO HOMEM*
}

\author{
Jelson Roberto de Oliveira** \\ jelsono@yahoo.com.br
}

RESUMO O presente artigo pretende analisar a relação entre o pensamento de Nietzsche e o movimento trans-humanista, cuja força teórica alargou-se durante as primeiras décadas do novo milênio, amparada na crescente história de êxitos da biotecnologia. Pretende-se apresentar uma posição crítica à apropriação que o trans-humanismo vem fazendo do pensamento do autor de "Assim falou Zaratustra". O foco da análise é o programa de autossuperação do homem, que será analisado a partir de três eixos centrais: a ideia de natureza e de liberdade; o problema dos valores; e a questão do aperfeiçoamento promovido pela bioengenharia e suas consequências para o destino do homem. Presume-se, assim, não dar conta da amplitude e complexidade da temática, mas oferecer pistas para enfrentar a questão sob o viés da relação de continuidade entre o niilismo e a técnica contemporânea, nesse caso, do ponto de vista antropológico.

Palavras-chave Nietzsche, trans-humanismo, pós-humanismo, além-dohomem, niilismo, biotecnologia.

ABSTRACT This article aims to analyze the relationship between Nietzsche's thought and the transhumanist movement, whose theoretical strength built up during the first decades of the new millennium, supported

* O presente ARTIGO é parte dos resultados da pesquisa de pós-doutoramento realizada na University of Exeter, UK, com apoio da CAPES (Processo BEX 6115/15-2).

** PUC/PR. Artigo recebido em 22/02/2016 e aprovado em 25/05/2016. 
by biotechnology's growing success history. It is intended to provide a critical position to the appropriation that transhumanism is doing of the thought of the "Thus Spoke Zarathustra's" author. The focus of the analysis is the program of self-overcoming of man, which will be analyzed from three central pillars: the idea of nature and freedom; the issue of values; and the issue of the improvement promoted by bio-engineering and its consequences for the destiny of man. It is assumed, therefore, it cannot account for the magnitude and complexity of the thematic, but it may offer clues to address the issue under the bias of continuity between nihilism and the contemporary technique, in this case, from the anthropological point of view.

Keywords Nietzsche, transhumanism, posthumanism, superhuman, nihilism, biotechnology.

\section{Introdução}

Desde que o dramaturgo irlandês George Bernard Shaw escreveu, em 1903, a sua peça "Man and superman", vários anos se passaram até que alguns teóricos do trans-humanismo seguissem suas pistas e aderissem à filosofia nietzschiana, acomodando o pensamento do filósofo alemão às bases teóricas de suas utopias, ficções e profecias. ${ }^{1}$ Muito dessas apropriações gira em torno do conceito de Übermensch e da ideia de superação do homem (ZA, "Prólogo", 3)² proposta pelo autor de "Assim Falou Zaratustra", dando azo a mais um capítulo das inúmeras e controversas assimilações que a obra nietzschiana sofreu ao longo dos anos, desde quando sua irmã Elizabeth Foster Nietzsche editou seu pensamento sob os auspícios do nacional-socialismo. O pensamento de Nietzsche, na maior parte dos casos, permanece obnubilado pelo afã de legitimidade que esses movimentos mantêm, algo que, como sugeriu Ansell Pearson (2011, p. 1), pode-se debitar à própria complexidade do conceito e ao fato de que Nietzsche, como the é próprio, não lhe tenha dado um acabamento final, abrindo margem

1 Para uma análise mais aprofundada do fenômeno (ou o efeito) Nietzsche no teatro, no cinema e na televisão (parte da assimilação da imagem e do pensamento do filósofo pela cultura pop), ver BABICH (2015). Obviamente, o ícone do Nietzsche super-homem (super-herói) prevaleceu no imaginário popular, associado a essa tendência para a superação do homem.

2 Usaremos neste trabalho as siglas convencionais para a citação das obras de Nietzsche: HH ("Humano, demasiado humano"); OS ("Miscelânea de Opiniões e Sentenças"); AS ("O Andarilho e sua sombra"); GC ("A Gaia Ciência"); BM ("Além do Bem e do Mal”); A ("Aurora”); GC ("A Gaia Ciência"); KSA ("Sämtliche Werke. Kritische Studienausgabe" - edição crítica em 15 volumes organizada por Giorgio Colli e Mazzino Montinari); ZA ("Assim Falou Zaratustra"); GM ("Para a Genealogia da Moral"); EH ("Ecce Homo") e Cl ("Crepúsculo dos ídolos"). Os demais textos serão referenciados segundo o sistema autor-data. 
para uma ampla variação hermenêutica ao longo desses dois séculos posteriores à publicação de suas obras. O próprio Ansell Pearson lembra (2001, p. 4) que, em "Ecce Homo", Nietzsche refere-se ao Übermensch como uma "palavra muito pensativa", ou "que faz pensar muito" [ein sehr nachdenkliches Wort]. Esse "dar a pensar" seria, por isso, parte da complexidade do conceito que faz com que o "além-do-homem [seja] uma nova imagem não-dogmática do pensamento: uma sedução, uma tentação, um experimento e uma esperança" (Pearson, 2011, p. 5). Por não ser dogmático e fechado, o Übermensch é uma espécie de conceito "modesto", um tipo de "pensiero debole" (pensamento fraco, porque não porta nenhum conteúdo fechado), para usufruir da expressão de Vattimo. Não é estranho, portanto, que um tal conceito conste em diversos - e divergentes - programas filosóficos pós-Nietzsche, ${ }^{3}$ entre os quais estão os trans-humanistas, cujas insistentes afirmações fazem de Nietzsche um transhumanista avant la lettre.

Como mais uma ideologia, ${ }^{4}$ o trans-humanismo parte da convicção de que a espécie humana (como todas as outras, ademais), não é "eternamente fixada e imutável" (Sorgner, 2009, p. 31) e que é preciso, por isso, superar os supostos limites impostos ao homem pela natureza, contando, para isso, com os potenciais tecnológicos do mundo contemporâneo. Sua tese central é que as realizações da racionalidade técnica levarão a uma fusão entre a tecnologia e a biologia, elevando os seres vivos (os humanos em especial, mas não exclusivamente) a um novo patamar da sua história evolutiva, principalmente com a ampliação das faculdades cognitivas, sensoriais e motoras, que passariam a ser controladas em favor da felicidade geral. Um dos seus arautos, o filósofo John Harris, fala, por exemplo, de um "claro imperativo de transformar o mundo em um lugar melhor" (2007, p. 4), enquanto Nick Bostrom (2005, p. 277) destaca o "urgente e gritante imperativo moral" de encontrar a cura da morte, e Gregory Stock acredita ser necessário "tomar o controle do nosso futuro evolutivo" (2002, p. 2).

3 Penso aqui especificamente em como Heidegger, Derrida, Deleuze, Foucault, Vattimo e mesmo Sloterdjik, por exemplo, apropriaram-se desse conceito.

4 Uso a expressão ideologia aqui no sentido lato, para expressar o fato de que o trans-humanismo apresenta-se como uma teoria mas, sobretudo, como uma militância: além de eventos e publicações (livros de filosofia, romances e toda uma série de panfletos e artigos impressos e, sobretudo, divulgados on-line), os transhumanistas organizam-se atualmente em vários institutos de pesquisa (entre os quais está o Future of Humanity Institute, de Oxford, e o Institute for Ethics and Emerging Technologies, entre outros) e mantém uma associação internacional (Humanity, World Transhumanist Association, cujo lema é bastante sugestivo: para o uso ético da tecnologia para ampliar as capacidades humanas; don't limit your challeges, challenge your limits [não limite os seus desafios, desafie os seus limites] - cujo site é humanityplus.org) e, no caso do Reino Unido, fundaram, em 2014, o Partido Trans-humanista (<www.transhumanistparty.org >), cujo presidente é Zoltan Istvan, autor de "The Transhumanist Wager", um romance publicado em 2013, que apresenta de forma resumida as chamadas "leis" do movimento trans-humanista. 
Nesse sentido, a perspectiva trans-humanista, dando-se crédito às afirmações de seus principais teóricos, por recorrer ao vocabulário tradicional (imperativos, obrigações e urgências), parte já de uma perspectiva moral. Eis o primeiro ponto que denuncia o distanciamento desse movimento em relação ao pensamento de Nietzsche, ao contrário do que pretendem os seus emissários. Isso porque essas posições, sendo já moralizadas: [1] alimentam uma visão negativa em relação ao mundo e a tudo o que é animal, corporal, humano e sexual e, ao mesmo tempo, seus arautos acreditam, paradoxalmente, que a legitimidade de uma tal posição encontra-se na própria natureza do homem, aquele que nasceu para vencer/superar a si mesmo; elas, além disso, [2] ocorrem como expressão já de uma determinada moralidade e, nesse sentido, não colocam os próprios valores em questão (e se alinham, como tal, à história da décadence denunciada por Nietzsche), o que faz com que o trans-humanismo seja apenas mais uma forma de "moral", uma forma da moral que vigora no Ocidente desde Sócrates, a moral da correção e da negação da vida; e, finalmente, [3] a engenharia genética e todas as potencialidades tecnológicas do mundo contemporâneo não seriam senão expressão da natureza racional do homem, pois teria sido a própria natureza a torná-lo hábil, a promover a sua autossuperação, cujo resultado seria a realização plena da vocação humana (uma tarefa de cunho estritamente racional que Nietzsche recusaria por completo). Analisemos cada uma dessas três perspectivas com o intuito de apresentar não apenas os erros interpretativos do trans-humanismo, mas, sobretudo, as divergências entre suas ideias e a filosofia nietzschiana.

\section{Superar os limites da natureza: liberdade e aperfeiçoamento humano}

Babette Babich (2011, p. 38) apontou, acertadamente, que o trans-humanismo é apenas mais uma expressão do ideal ascético criticado por Nietzsche, uma expressão do ódio a tudo o que é natural, por meio de ficções como perfeição e imortalidade. E mais, que suas promessas são "a última palavra" para o diagnóstico de Gunther Anders, em "A obsolescência do homem": "uma precipitada convicção de um ethos mundial consumista e capitalista". Segundo Babich, "a obsolescência do homem é parte e parcela da obsolescência de todas as coisas, inclusive música e filmes da indústria cultural da mídia, que nós 'consumimos' ao invés de 'aproveitarmos"' (2011, p. 38).

Ora, o que é obsoleto no homem é a sua natureza, ou seja, tudo o que nele ainda é biofisiológico. É ela que deve ser "superada", "vencida", "descartada". Considerada negativamente pelos teóricos do trans-humanismo, os quais afirmam, no geral, que toda a honra do homem estaria em submetê-la aos seus poderes, 
limitá-la e orientá-la segundo as suas necessidades, interesses e prazeres, ${ }^{5}$ a natureza é algo a ser suplantado. Tratar-se-ia de uma afirmação radical da grande liberdade humana diante dos grilhões naturais: vencida a natureza, o homem estaria finalmente livre para aperfeiçoar a si mesmo e editar o mundo para torná-lo "o melhor dos mundos possíveis". Limitando a natureza (na sua expressão biofisiológica e genética), chegaríamos a realizar a verdadeira natureza do homem (na sua expressão racional) e, ao fazê-lo, no ato mesmo de nossa resistência, acabaríamos por proteger e honrar o que nos é próprio. Tudo se passa como se o homem tivesse a obrigação de terminar (acelerar e melhorar) o serviço da natureza que ficou incompleto. Apoiados na afirmação de Nietzsche de que homem seria um "animal indeterminado" [das noch nicht festgestellte Tier] (KSA 11, 25 [428], de 1884, p. 125), os trans-humanistas acreditam que caberia a ele mesmo, com as ferramentas fornecidas pela moderna tecnologia, de-terminar a si mesmo, completar as faltas e corrigir os defeitos. $\mathrm{O}$ homem, nesse caso, carregaria as oportunidades que foram interditadas a todos os demais seres na forma da possibilidade de re-configurar a si mesmo, algo que, no limite, faria parte de suas obrigações éticas e ganharia legitimidade na exigência da própria natureza, que lhe teria facultado tal poder de remanejar todas as esferas do ser. Nas mãos do homem, portanto, a manipulação da sua natureza e da natureza em geral, torna-se uma obrigação, uma parte central de sua vocação biotecnológica em busca do aprimoramento da(s) espécie(s). Nessa função, cumpriríamos como nunca, inclusive o próprio preceito bíblico, presente no livro do "Gênesis", que ordena o domínio do homem sobre todos os demais seres. Só o poder biotecnológico possibilitaria o cumprimento dessa prescrição divina, com a diferença de que, agora, depois da morte de Deus, o homem cumpre os desígnios e os objetivos que ele mesmo - e ninguém mais - impõe a si. A reivindicação da liberdade, nesse caso, caminha de mãos dadas com o poder de fazer, refazer e reconfigurar o homem, um poder cada vez mais carente de responsabilidade.

Ocorre que o "nós" que inventou os objetivos é um ser provisório, partícipe do processo sobre o qual ele quer interferir e, ao mesmo tempo, sendo interino, ele está afetado pelos limites que ele mesmo pretende vencer e que impedem a pretensa clareza sobre o futuro. A imanência, portanto, dos objetivos, deveria sinalizar para o perigo do programa de "aprimoramento" justamente onde esses objetivos são influenciados pelos limites do presente, os valores e as necessidades

5 O trans-humanismo mantém uma face hedonista (de matiz utilitarista) bastante evidente, que chega mesmo a funcionar como um fio condutor de suas teorias: se ele não está, necessariamente, ligado à maior felicidade geral para todos, está, pelo menos, articulado à ideia de diminuição geral do sofrimento. 
do homem de agora. Em outras palavras: sobre qual fundamento afirma-se que determinado procedimento deve ser realizado em vista de algum pretenso benefício que seja duradouro o suficiente e a tal ponto satisfatório no tempo e no espaço, que compense os perigos que ele veicula consigo, inclusive aqueles que fazem parte da sua gênese cumulativa e, nesse caso, em absoluto retroativa? Uma tal posição não seria apenas mais um reflexo do "defeito hereditário dos filósofos", ou seja, da sua "falta de sentido histórico" (HH, 2)? Obviamente, aqui, como insistiu Hans Jonas ao longo de sua obra, a vocação do poder deveria ser também a vocação da responsabilidade, algo que parece se contrapor, de alguma forma, à propagada inocência do homem contemporâneo, diante de um mundo destituído de finalidade e de valor, sobre o qual paira a sombra do Deus morto. Muitas afirmações dos trans-humanistas traem a autorreconhecida tarefa de avaliar as benesses da tecnologia e parecem render-se ao discurso utópico que, na maior parte das vezes, ofusca as consequências negativas da ação tecnológica.

Obviamente, não há de ser negada a importância e a validade do esforço humano em vista do melhoramento de si e do mundo ao redor. A questão tem a ver com o melhor modo para que essa tarefa seja realizada, sem que a herança biológica, justamente aquilo que nos resta de "menos reconstruível"“ de tudo, que é a vida - inclusive a humana - possa ser preservada, não apenas do ponto de vista existencial-ontológico, mas em sua autenticidade. Na medida em que a técnica transformou-se em um conhecimento orientado para a manipulação do mundo, a pergunta ética tem sido paulatinamente associada ao conservadorismo e ao anacronismo. Vários autores do passado, entre os quais está Pico della Mirandola e, de alguma forma, o próprio Nietzsche, afirmaram a necessidade de aprimoramento moral do ser humano. O que agora se projeta nos laboratórios e nas teorias dos trans-humanistas é, contudo, algo jamais imaginado: se a moral é, também, uma tentativa de resistência do homem diante da natureza, a tecnologia contemporânea oferta um caminho muito mais poderoso e, por isso, muito mais perigoso, que pretende projetar o homem além da (sua) natureza. A tecnologia é, em relação à moral, um caminho aparentemente mais eficaz, cujo resultado é o desbloqueio de muitas (novas) possibilidades. O risco do uso desse instrumento em nome da liberdade em contraposição à natureza não é outra coisa senão a perda da própria liberdade, reconhecida como parte da própria natureza e não necessariamente a sua antítese. Tratar-se-ia, ainda, de um de todos os 'recursos': a incrivelmente rica dotação genética depositada pelas eras da evolução" (Jonas, 2006, p. 36). 
homem livre, o homem fabricado em laboratório, cuja sexualidade é mediada por dispositivos tecnológicos e cuja felicidade depende da administração de fármaco-químicos capazes de controlar seus humores, sonhos e instintos, e de orientar seus desejos? Tratar-se-ia de um homem livre, ainda, aquele que foi encomendado por seus pais, manipulado geneticamente em mínimos detalhes, para evitar todo acaso natural? Tratar-se-ia de um homem livre, aquele que, tendo-se reprogramado, prolongado seu tempo de vida e, finalmente, se curado da morte ${ }^{7}$ - caminhando, depois disso, sem destino, mas também sem frustração, boquiaberto diante das mesmas paisagens e companhias? Seria, no fim, ainda liberdade a oferta do trans-humanismo?

Como apontou Michael Hauskeller, no seu recente livro "Mythologies of Transhumanism", principalmente o capítulo IV, intitulado "Stealing Fire from the Gods" ("Roubando o fogo dos deuses", uma referência óbvia ao mito de Prometeu), perguntados sobre "por que nós deveríamos desejar viver tanto, para que uma vida radicalmente estendida é boa, então frequentemente eles nos dirão que nós precisamos uma vida mais longa a fim de sermos capazes de realizar as muitas possibilidades da existência"8 (2016, p. 30). Trata-se, portanto, de uma liberdade radical, entendida como capacidade de realizar todas as possibilidades da existência, algo que estaria guardado de forma extraordinária, na promessa da imortalidade. Imortais, não estaríamos mais apenas obrigados à realização daquelas possibilidades de uma vida individual e provisória de um ser indeterminado. Não teríamos, com esse processo, contudo, aberto um campo irrestrito no qual a própria ideia de liberdade esvanece? Haveria sentido em pensar a liberdade no campo da imortalidade, se carecêssemos de uma finalidade diante de uma abertura infinita de possibilidades? Nesse caso, a abertura à eternidade carregaria consigo a obrigação de nos tornarmos, finalmente, seres completos, ou seja, perfeitos, mas, ao mesmo tempo, não estaríamos condenados a nunca realizar uma tal perfeição simplesmente pelo fato de nunca morrermos, ou seja, de nunca fecharmos o ciclo? Se a indeterminação é o "núcleo formativo da natureza humana" (Hauskeller, 2016, p. 31), algo que, no fim, garante tão somente a ausência de uma natureza em sentido estrito, então, no campo da imortalidade, somos forçamos a reconhecer esse fato com maior vivacidade. Nesse caso, então o trans-humanismo não teria superado a indeterminação, mas,

7 No aforismo 180 de "Humano, demasiado humano", Nietzsche mostra-se contrário a esses processos ao escrever: "o anseio de prolongar dia a dia a existência, com angustiante assistência médica e as mais penosas condições de vida, sem força para se aproximar do verdadeiro fim, é algo muito menos respeitável”.

8 Essa seria a posição, por exemplo, de Harrington (1969, p. 182) e James Stacey Taylor (2009, p. 109), citados por Hauskeller, que reconhecem o envelhecimento e a morte como "constrangimentos biológicos" da autonomia humana. Esse é um posicionamento bastante retomado pelos trans-humanistas. 
justamente ao contrário, teria a levado ao extremo, ao tempo em que o aumento da indeterminação conduziria a humanidade até um ser humano melhor, tal como evocado pelos ideólogos desse movimento. O contrário seria reconhecer que a indeterminação, ou mesmo a imperfeição e a incompletude, não seria característica do ser humano do presente, mas parte mesmo da "natureza" do ser humano em geral.

No meu ponto de vista, tais posições não encontram nenhum apoio na filosofia de Nietzsche. Para o filósofo alemão, a negação da natureza, por meio dos vários processos de "melhoramento" impetrados ao longo dos tempos, acabou por enfraquecer e adoecer o próprio homem. Ele é muito claro quanto a isso, por exemplo, em uma conhecida passagem do "Crepúsculo dos Ídolos":

Em todos os tempos quis-se "melhorar" os homens: este anseio antes de tudo chamavase moral. Mas sob a mesma palavra escondem-se todas as tendências mais diversas. Tanto a domesticação da besta humana quanto a criação de um determinado gênero de homem foram chamadas "melhoramento": somente estes termos zoológicos expressam realidades. Realidades das quais com certeza o sacerdote, o típico "melhorador", nada sabe - nada quer saber... Chamar a domesticação de um animal seu "melhoramento" soa, para nós, quase como uma piada. Quem sabe o que acontece nos amestramentos em geral duvida de que a besta seja aí mesmo "melhorada". Ela é enfraquecida, tornam-na menos nociva, ela se transforma em uma besta doentia através do afeto depressivo do medo, através do sofrimento, através das chagas, através da fome. - Com os homens domesticados que os sacerdotes "melhoram" não se passa nada de diferente (CI, Os "melhoradores" da humanidade, 2).

Certamente poderíamos incluir o trans-humanismo entre as "tendências mais diversas" do projeto de melhoramento criticado por Nietzsche e, por essa via, também por ele alcançaríamos o adoecimento do homem. Isso porque, como ocorrera nos projetos do passado, também agora a moralidade é colocada a serviço da negação das características humanas, demasiado humanas, principalmente no que elas teriam de aproximação com o animal do homem, ou seja, com a sua animalidade. Nesse sentido, o trans-humanismo também pretende "amestrar o animal de rapina 'homem', reduzi-lo a um animal manso e civilizado, doméstico" (GM, I, 11), algo que já foi tentado pela moral socrático-platônico-judaico-cristãiluminista com o prejuízo de ter enfraquecido e anulado no homem justamente aquelas forças vitais mais relevantes, levando àquilo que Nietzsche chamou de "má-consciência" e mesmo de "ressentimento": "a "má-consciência' separou o homem do seu passado animal, exterminando os seus velhos instintos, nos quais até então se baseava sua força, seu prazer e o temor que o inspirava" (GM, III, 73). Em outras palavras, ao negar a sua natureza, o homem negou a sua própria animalidade e, voltando-se contra si mesmo, "impacientemente lacerou, perseguiu, corroeu, espicaçou, maltratou a si mesmo" e, mais ainda, como um 
"animal que querem 'amansar"”, o homem passou a se ferir "nas barras da própria jaula", tornou-se "carente, consumido pela nostalgia do ermo, que a si mesmo teve de converter em aventura, câmara de tortura, insegura e perigosa mata esse tolo, esse prisioneiro preso da ânsia e do desespero tornou-se o inventor da "má consciência"' (GM, II, 15). Preso pelos projetos de melhoramento, o homem se consumiu e se enfraqueceu, deixando-se corroer pela culpa de ter sido, ele mesmo, o responsável por tal empreendimento de sofrimento. Eis como a guerra contra a natureza leva ao adoecimento do homem segundo Nietzsche e como, nesse sentido, os projetos de aperfeiçoamento propostos pelo transhumanismo não podem ser associados às ideias deste que foi, entre os filósofos, um dos maiores críticos da moral do melhoramento.

\section{O Übermensch e superação do homem: o problema dos valores}

Como afirmamos anteriormente, o esforço dos trans-humanistas tem sido o de encontrar semelhanças entre o conceito nietzschiano de Übermensch e o seu projeto de aperfeiçoamento do ser humano e, alguns deles, como demonstra Hauskeller, chegam a afirmar que, sem Nietzsche, esse movimento sequer existiria:

Nick Bostrom $(2005 a, 4)$ acertou quando ele afirmou que há apenas semelhanças em nível de superfície entre a visão de Nietzsche do Übermensch (super-homem, ou super-humano) e a concepção trans-humanista do pós-humano. No entanto, outros, mais tarde, argumentaram que as semelhanças são na verdade "significativas" e podem ser encontradas "em um nível fundamental" (Sorgner 2009, 29). ${ }^{9}$ Max More ainda admitiu ter sido fortemente influenciado por Nietzsche, fato que, em seguida, o levou à publicação de seu ensaio seminal "Trans-humanismo: Para uma filosofia futurista", de 1990 e inspirou o próprio nome do movimento: trans-humanismo (More 2010, 2). Sem Nietzsche, então, sem dúvida não haveria um movimento trans-humanista. No entanto, embora isto possa ser historicamente correto, há, de fato, algumas diferenças essenciais entre o trans-humanismo e a mitologia nietzschiana que não devem ser esquecidas (Hauskeller, 2016, p. 32).

O trabalho de Sorgner é especialmente curioso. Já nas primeiras páginas de seu artigo "Zaratustra 2.0 and Beyond: Further Remarks on the Complex Relationship between Nietzsche and Transhumanism", no qual ele essencialmente critica as posições de Babich, ${ }^{10}$ podemos ler, sem rodeios, a sua convicção: "eu

9 "Eu penso que podemos encontrar significativas similaridades entre o pós-humano e o sobre-humano [overhuman, a palavra usada por Sorgner para verter ao inglês o Übermensch] num nível bastante fundamental" (2009, p. 29).

10 O artigo de Sorgner é uma tréplica à crítica de Babett Babich publicada no artigo Nietzsche's Post-Human Imperative: On the "All-too-Human" Dream of Transhumanism, escrito como resposta ao próprio Sorgner 
espero que as reflexões e argumentos a seguir tornem mais óbvio que há uma similaridade estrutural entre os pontos de vista de Nietzsche e aqueles dos transhumanistas, mesmo que suas compreensões de mundo soem significativamente diferentes" (2012, p. 1). Seu esforço é desmontar a argumentação de Babich, em resposta a seu artigo anterior, com o fim de mostrar que, embora não seja possível associar diretamente o trans-humanismo a Nietzsche, seu pensamento estaria, obviamente, conectado com esse movimento em uma espécie de prenúncio. Isso porque, como ele anuncia no artigo "Nietzsche, the Overhuman, and Transhumanism", de 2009, ${ }^{11}$ o conceito nietzschiano de sobre-humano (ou além-do-homem, overhuman ou Übermensch) poderia preencher algumas lacunas que parecem existir nas teses trans-humanistas.

Para esses teóricos, o débito com Nietzsche seria pago por meio do investimento tecnológico em vista de aperfeiçoar o ser humano e, com isso, melhorar o mundo ao redor, algo que deve ser reconhecido como um "imperativo moral" capaz de "pavimentar o caminho" até a trans-humanidade. Tudo teria, nesse caso, começado com o diagnóstico de Nietzsche sobre a indeterminação do homem e o anúncio da sua necessária superação, em direção do além-dohomem. Uma tarefa que teria, pelas mãos dos trans-humanistas, deixado de ser meramente ético-existencial e se tornado propriamente biotecnológica. Essa tentativa de aproximação em relação a Nietzsche, obviamente, deixa de lado, mais uma vez, algumas das posições centrais da filosofia nietzschiana, entre as quais aquela que recusa qualquer tipo de melhoramento do ser humano, ainda mais quando uma tal proposta está amparada numa visão "moralizada" da vida, ou seja, ancorada em alguma prévia interpretação sobre o "bem e o mal", como é o caso quando se nega a "natureza" do homem. Nietzsche mesmo escrevera:

Melhorar a humanidade? Eis a última coisa que eu prometeria. Não esperem de mim que eu erija novos ídolos! Que os antigos aprendam antes quanto custa ter pés de barro! Derrubar "ídolos" - é assim que chamo todos os ideais -, esse é meu verdadeiro ofício. É inventando a mentira de um mundo ideal que se tira o valor da realidade,

e publicado na revista The Agonist. Além disso, no referido texto, Sorgner analisa as posições de Paul S. Loeb (no seu Nietzsche's Transhumanism), com as quais ele próprio se alinha. O artigo de Ansell Pearson, supracitado, ao analisar a importância do texto de Sorgner e da discussão por ele apontada, afirma que: "as questões levantadas por seu trabalho são de vital importância e merecem a atenção do leitor sério de Nietzsche, inclusive porque elas nos convidam a refletir sobre as preocupações mais profundas do próprio Nietzsche e o sentido e significado de seus ensinamentos mais fundamentais" (2011, p. 16). Todos esses textos podem ser facilmente consultados no site do Institute for Ethics and Emerging Technologies, sob o título de Was Nietzsche a Transhumanist? (<http://ieet.org/index.php/IEET/print/5691>). O IEET é uma organização sem fins lucrativos com sede nos Estados Unidos fundada em 2004 pelo filósofo Nick Bostrom e o bioeticista James J. Hughes, com o objetivo de promover o debate em torno das potencialidades do "tecnoprogresso" e de suas consequências.

11 E ao qual Michael Hauskeller respondeu em 2010 com o texto: "Nietzsche, the Overhuman and the Posthuman: A Reply to Stefan Sorgner". 
sua significação, sua veracidade... A mentira do ideal foi até agora a maldição que pesou sobre a realidade, a própria humanidade se tornou mentirosa e falsa até o mais fundo de seus instintos - até a adoração dos valores opostos àqueles que poderiam lhe garantir um belo crescimento, um futuro (EH, "Prólogo", 2).

Assim, se pudermos retomar o pensamento de Nietzsche com alguma fidelidade, o projeto de aperfeiçoamento teria, contrariamente ao que se pretende, um cunho ainda metafísico-moralizante: primeiro porque acredita numa ideia de perfeição; segundo, porque tal ideia está fundada em uma visão moralmente negativa da condição/natureza humana e do mundo até o presente, que inclui uma ideia de natureza tida como "má" em relação à tarefa humana, que seria conduzida pelas "boas" intenções de seus agentes.

Isso nos leva a uma questão central no pensamento de Nietzsche que parece não ser levada em conta pelos seus defensores trans-humanistas: o problema da reavaliação dos valores. Eles parecem fechar os olhos para o motivo da recusa nietzschiana da ideia de melhoramento, que aparece de forma muito clara em "O Crepúsculo dos Ídolos" ("Incursões de um intempestivo", 9): os "melhoradores da humanidade estão injetados de moralidade". Apesar de as promessas de aperfeiçoamento partirem de uma insatisfação com o homem como ele foi até agora, a projeção do "melhor" está pautada por uma noção de valor derivada do passado. Para os trans-humanistas, os próprios valores projetados para esse "novo" homem poderiam ser os mesmos do homem de agora. Bostrom (2005, p. 5), por exemplo, postula, literalmente, que "os valores pós-humanos podem ser os nossos valores atuais". Viver mais, de forma saudável e feliz parece, de fato, não ter nada de novo quanto aos valores que a humanidade cultivou até agora na maior parte das culturas. A promessa trans-humanista, assim, caracteriza-se como uma repetição dos valores e, com isso, dos mesmos equívocos e erros que acompanharam os outros projetos desse tipo ao longo da história do ocidente e que Nietzsche diagnosticou como história de uma doença, aquela que levou ao cansaço do homem consigo mesmo, ou seja, o niilismo.

Nesse sentido, ao manter-se nos mesmos parâmetros de valores que vigoraram até agora, os trans-humanistas não devem nada a Nietzsche, justamente ao contrário. Como "primeiro moralista", o autor de "Para a genealogia da moral" se anunciou como uma "dinamite" e um "destruidor par excellence" dos valores vigentes, a começar por aqueles que foram considerados como os mais indesejados e desvantajosos para uma cultura que carrega consigo os ideais gregários como valores supremos. Nietzsche reconheceu esses valores vigentes como "hostis à vida": "contrário aos sentidos, aos instintos, à natureza, ao animal, em suma, os ideais até agora vigentes, todos ideais hostis à vida, difamadores do mundo" (GM, II, 24). Isso porque a domesticação do homem 
sempre foi orientada, segundo Nietzsche, por um modelo de vida cuja referência é o rebanho e, consequentemente, cuja necessidade foi derrotar justamente aquelas forças naturais que tornavam o homem capaz de viver em solidão e em cultivo de si. Também agora, com o trans-humanismo, a moralidade seguiria sendo, na medida em que reflete o imperativo utilitarista da felicidade geral ou, pelo menos, do mínimo sofrimento para o maior número possível de pessoas, "o instinto gregário no indivíduo" (GC 116). Todos os processos de melhoramento projetados pela via biotecnológica, além disso, evocam o grave risco da padronização, fazendo com que a guerra contra a animalidade seja, por isso, uma guerra contra o "pathos de distância" (GM I, 2), contra as forças que tornavam o homem capaz de viver em solidão, ou seja, de distanciar-se dos valores vigentes. Tais valores, assim, não são outros senão aqueles derivados da ascensão do ideal da vida gregária nas suas mais variadas formas - como moral da "conformidade", da "conciliação", da "harmonia", da "baixeza" e da "igualdade":

o que aqui se julga saber, o que aqui se glorifica com seu louvor e seu reproche, e se qualifica de bom, é o instinto do animal de rebanho homem: o qual irrompeu e adquiriu prevalência e predominância sobre os demais instintos, fazendo-o cada vez mais, conforme a crescente aproximação e assimilação fisiológica de que é sintoma. Moral é hoje, na Europa, moral de animal de rebanho (BM, 202).

Todo projeto que pretenda a felicidade geral, portanto, repercutiria esse velho ideal que transformou a fraqueza do homem em virtude, com o preço de ter adoecido o animal-homem. Como fez a religião, por exemplo, também o movimento trans-humanista, na sua insatisfação com a "natureza" do homem, oferece-lhe um "consolo" na forma de uma "fantasmagoria da bem-aventurança futura antecipada" que um dia se chamou Reino de Deus e que, agora, apresentase com as várias facetas da realidade pós-humana. O procedimento continua o mesmo: a constituição do ideal de felicidade para todos em um "depois", constituído a partir dos valores vigentes até agora, fundamentados em um pretenso processo de melhoramento que mal esconde a transformação da fraqueza (individual) em virtude (coletiva):

"a fraqueza é mentirosamente mudada em mérito"; a impotência que não acerta contas é mudada em "bondade"; a baixeza medrosa, em "humildade"; a submissão àqueles que se odeia em "obediência"; a própria covardia, no qual é pródigo [...], recebe aqui o bom nome de "paciência"; sua miséria é uma eleição e distinção por parte de Deus; a isto chamam "bem-aventurança", "beatitude" (GM, I, 14).

Todos os valores que guiam a gregariedade transformada em virtude por excelência seriam sintomas da décadence cultural. Tornar-se um além-do- 
homem, em sentido nietzschiano, passaria necessariamente pela recusa desses valores, pela indiferença em relação ao que até agora se entendeu como bem e mal. De fato, os trans-humanistas parecem não aceitar uma posição tão radical, porque, como aponta Hauskeller (2016, p. 35), eles "dão continuidade à tradição logocêntrica da filosofia ocidental" e ao fato de que a "mente", ou seja, o "intelecto", é algo que deve ser ampliado a tal ponto de superar e tornar obsoleto o corpo, em uma evocação clara do antigo dualismo amplamente criticado por Nietzsche. Ser consciente seria, nesse caso, sinal de plenitude de seres capazes de agir de forma racional e autônoma, dominando e orientando racionalmente tudo o que está à sua volta, incluindo o seu próprio corpo: “e porque nossa essência consiste em nosso pensamento é, afinal, concebível que possamos um dia ser capazes de transferir ['upload'] nosso verdadeiro ser para um computador (ou para outro cérebro biológico) e, assim, alcançar algum tipo de imortalidade pessoal" (Hauskeller, 2016, p. 36).

Nesse caso, as promessas passam por uma tentativa de "substituição" do corpo orgânico, reconhecido como o lugar por excelência de atuação dos chamados limites naturais. O corpo, nesse caso, torna-se obsoleto porque nele residem os instintos. $\mathrm{O}$ trans-humanismo, consequentemente, dá sequência à tradição de desvalorização do corpo que atravessa a nossa história cultural, vindo a fundar, amparado em uma impressionante história de êxitos, possibilidades reais de que isso venha de fato a acontecer. Nunca a ideia de que a mente, prova de nossa identidade divina ou naturalmente superior (algo afinal, separado do corpo), atuou de forma tão eficaz para a reconfiguração do homem. Uma tal "mentira" (segundo Nietzsche) não passaria de um "sintoma de imperfeição", já que o homem é "inteiramente corpo e nada além disso", uma "grande razão", como ele escreve em "Assim falou Zaratustra":

o corpo é uma grande razão, uma multiplicidade com um só sentido, uma guerra e uma paz, um rebanho e um pastor. Instrumento de teu corpo é também tua pequena razão que chamas 'espírito', meu irmão, um pequeno instrumento e brinquedo de tua grande razão. 'Eu', dizer tu, e tens orgulho dessa palavra. A coisa maior, porém, em que não queres quer - é teu corpo e sua grande razão: essa não diz Eu, mas faz Eu (ZA, "Dos desprezadores do corpo", 1).

Nietzsche é claro: não há um eu que já não seja corporal e, por isso, não há um homem que também não seja corporal. Atuar sobre o corpo orgânico no sentido de torná-lo "melhor" até que, enfim, ele se torne "obsoleto" e transferível a outro receptáculo que não seja o seu próprio corpo, com o qual ele se confunde desde sempre, seria alterar esse dado central, com todos os custos quanto ao adoecimento do homem, conforme vimos até aqui. 
Essa tarefa teria sido assumida de forma prioritária pelo trans-humanismo como parte de sua tentativa de "salvar vidas" (Bostrom, 2005, p. 9), ou seja, impedir que os seres humanos continuem envelhecendo e morrendo, já que o corpo é o lugar e, ao mesmo tempo, o culpado por esse acontecimento. Os avanços da medicina, nesse sentido, seriam meros sintomas da mesma rebeldia contra a corporeidade do homem. Obviamente é preciso reconhecer que nenhum de nós quer morrer, e que seria muito "bom" continuar vivendo, principalmente se o cenário também "melhorasse" ou se ampliasse. Contudo, devemos nos perguntar sobre o impacto disso para toda a espécie, enquanto Nietzsche nos faz notar a insignificância da maior parte de nós e se pergunta mesmo sobre o fato de que, talvez, muitos não deveríamos ter sequer nascido porque nunca, de fato, aprendemos a viver de forma plena. Com Nietzsche também podemos nos perguntar, nesse caso: quanto vale não morrer e, caso isso seja um dia alcançado, quem mereceria tal bênção? Nietzsche, a nosso ver, seria contrário à primeira das perspectivas orientadoras de uma possível solução para essa questão: a ideia de igualdade, ou seja, o fato de que todos mereceríamos não morrer, uma das bases éticas apontadas como saída para a questão da chamada "cura da morte" pelos próprios trans-humanistas. Para o filósofo, a igualdade é parte do erro que transformou o ego e, consequentemente, o egoísmo, em um contravalor ou, na linguagem tradicional, em um vício. Para que todos sejam iguais, é preciso que todos neguem o seu próprio ego, algo que Nietzsche recusa insistentemente. Para ele, a ideia mesmo de igualdade não passa de um sintoma de decadência:

A "igualdade", uma certa assemelhação factual que só ganha expressão no interior da teoria dos 'direitos iguais', pertence essencialmente à decadência: o fosso entre homem e homem, estado e estado, a multiplicidade de tipos, a vontade de ser si próprio, de destacar-se, isto que denomino como Pathos de Distância: tudo isto é próprio a todo tempo forte (CI, "Incursões de um Extemporâneo", 37).

A pretendida igualdade diante da imortalidade seria, assim, um novo equívoco, porque a superioridade do homem não estaria em não morrer, mas em "aprender como viver e como morrer" - nesse sentido, "os trans-humanistas, segundo Nietzsche, não entenderam nada" (Hauskeller, 2016, p. 36). Nietzsche não se deixaria confundir com "esses pregadores da igualdade" porque a sua ideia de justiça passa pela noção de hierarquia e pela afirmação da singularidade de cada indivíduo: “'Os homens não são iguais'. [...] Por mil pontes e passarelas deverão eles afluir para o futuro, e cada vez mais guerras e desigualdades haverá entre eles: assim me leva a falar meu grande amor!" (ZA, "Das Tarântulas").

Em resumo, a filosofia de Nietzsche estaria, por exemplo, completamente dissociada do eixo central do projeto trans-humanista no que tange à conquista 
da felicidade, meta central da vida humana, travestida agora, de novo, de "melhoramento genético". Nietzsche nem está de acordo com a ideia de que a vida tenha uma meta nem sequer que esta meta seja a felicidade geral, afiançada pelos ideais utilitaristas do trans-humanismo. Esse movimento, nesse caso, não seria senão um desdobramento da tradição ocidental que remonta ao projeto socrático-platônico e mesmo cristão, agora contando com as crenças do Iluminismo desdobradas nos dispositivos tecnológicos.

\section{Depois do homem: homunculus ou Übermensch?}

Leitores menos atentos e talvez mais tendenciosos acabam encontrando em "Assim Falou Zaratustra" algumas afirmações e passagens que fariam de Nietzsche um advogado da causa trans-humanista. Em uma dessas passagens, já no prefácio, Nietzsche escreve: "o homem é, para mim, uma coisa demasiado imperfeita" (ZA, "Prólogo", 2). Ora, é preciso notar, em primeiro lugar, que tal afirmação não é de Zaratustra, mas do santo que se encontra com Zaratustra ao pé da montanha, e essa fala representa justamente a posição criticada por Nietzsche, aquela que levou à fuga do eremita para o alto da montanha. $\mathrm{Ou}$ seja, é a velha moral que vê o homem em sua imperfeição. E é interessante notar que é justamente esse homem, tal como é celebrado pelo humanismo vigente pela boca do santo e sua moral, precisa ser superado. É ao homem da "cidade", da "praça do mercado" (um símbolo da moral de rebanho), que Zaratustra anuncia: "Eu vos ensino o super-homem. O homem é algo que deve ser superado. Que fizestes para superá-lo?" (ZA, "Prólogo", 3). E mais, para Zaratustra, "o super-homem é o sentido da terra" e essa deve ser o alvo da vontade do homem, ou seja, superar a si mesmo, como um dia o homem superou o macaco (de quem agora se envergonha) e esse, por sua vez, superou o verme primitivo. As referências à teoria evolucionista são óbvias e - mais uma vez - legitimariam a posição trans-humanista. Deve-se, contudo, prestar atenção ao sentido de tal superação, tal como esse é exposto por Nietzsche logo em seguida: "Eu vos imploro, irmãos, permanecei fiéis à terra e não acrediteis nos que vos falam de esperanças supraterrenas! São envenenadores, saibam eles ou não. São desprezadores da vida, moribundos que a si mesmos envenenaram, e dos quais a terra está cansada: que partam, então!" (ZA, "Prólogo", 3). A superação, como se vê, não é resultado de um esforço de negação da realidade imanente à qual o homem pertence. O homem que precisa ser superado é o homem moralizado, aquele animal doméstico e fraco que teme o mundo (principalmente o mundo natural, incluída aí sua própria natureza e animalidade) e, por isso, quer construir uma rota de fuga da terra. A superação ensinada por 
Zaratustra não é outra senão aquela que denuncia a fraqueza e o cansaço do homem com a sua "natureza", escondida por trás das promessas blasonadas pelos “envenenadores" "e "desprezadores" da vida. O Übermensch, nesse sentido, jamais nasceria como uma negação da vida (ou da natureza), mas, ao contrário, de um gesto afirmativo daquilo que é humano (Menschliche) no homem e que não seria, nesse caso, aquele humano do humanismo corrente, que parte de uma tentativa de melhorar o humano, demasiado humano.

Precisamos notar, em segundo lugar, que a chamada superação do homem proposta por Nietzsche nunca alcançaria um ponto definitivo, um estado final de perfeição. O homem deve superar-se em um sentido de reconhecer-se a si mesmo como um processo e não como uma finalidade. Hans Jonas notou bem isso quando afirmou que Nietzsche

não era nenhum utopista e não alimentava nenhuma expectativa em relação ao estado futuro, nem muito menos em relação a um estado "definitivo", que significaria a morte da aventura humana. O estado transitório se referia estritamente aos seres humanos, ao esperado "super-homem" prontamente dito, que com sua vez deveria superar-se indefinidamente, em um horizonte aberto (Jonas, 2006, p. 259).

Mesmo reconhecendo que Nietzsche claramente "esperava pelo melhor", Jonas nega justamente aquilo que os trans-humanistas parecem afirmar: "não há nenhuma indicação em Nietzsche de como promover ou tornar possível o aparecimento do homem superior, e mesmo sequer quanto a sua probabilidade (salvo se quiséssemos recorrer às imagens ocasionais sobre domesticação)" (Jonas, 2006, p. 260). O tal "homem verdadeiro" de Nietzsche, identificado na análise de Jonas a respeito das utopias vigentes, não teria, assim, nada em comum com os projetos que fazem das tecnologias um caminho para a superação do homem, porque ele não deve ser reconhecido como uma finalidade, um sentido último de algum processo, mas justamente o contrário, como uma "ponte" sobre o abismo (ZA, "Prólogo", 2), algo transitório, um experimento (A, 453). Como transição, o homem contém tanto o animal que ele é (natureza) quanto o além-do-homem que ele ainda não é, mas pode se tornar. Há nele tanto o humano, propriamente dito, quanto o além-do-humano, ou seja, a abertura para o experimento que ele mesmo é. A transição, assim, não pode ser entendida como um processo que se dirige a algum sentido final. O sentido da transição está em ser propriamente a passagem.

A afirmação do humano, em Nietzsche, deve ser reconhecida em seu sentido antropológico, por assim dizer, e não ético, já que é fácil presumir que o humano que afirma a sua natureza é facilmente confundido com aquilo que a moral tradicional chama de desumano, já que lhe faltariam justamente as ataduras da 
moralidade: "o homem atual" [gegenwärtigen Menschen] seria o contrário do "humano-sobre-humano [menschlich Übermenschlichen], que com frequência parecerá inumano [unmenschlich]" (GC, 382). Como esclareceu Onate: "Humano significa no vocabulário nietzschiano uma modalidade específica de formações de domínio, cujas operações sensitivas, sentimentais, volitivas, pensantes devem ser encaradas apenas como símbolos da dinâmica de potência que nelas atua, pouco importando as resultantes psíquicas dessas operações” (2003, p. 31). Nietzsche, a começar pelo título de sua obra de 1878, "Humano, demasiado humano" ["Menschliches, Allzumenschliches"], na qual, como é sabido, ele recusa a metafísica e denuncia a falta de sentido histórico da filosofia, também quanto ao fato de que ela entende o homem de hoje (leia-se: o homem humanizado pelo humanismo) como se ele representasse o conceito mesmo de homem desde e para sempre. Nietzsche, dizíamos, pretende "colocar na luz sem se intimidar, a desrazão das coisas humanas" (KSA 8, 5 [20], de 1875, p. 45), ou seja, todas aquelas coisas humanas, demasiado humanas que são expressão da vontade de poder, mas que deveriam ser anuladas pela perspectiva moralizante.

Afirmar o humano, nesse caso, é trazer à luz a origem ilógica e necessária de todas as construções de valores, incluindo a própria ideia de homem, uma ideia que, no limite, é também um conceito moral e que, como "as maiores produções do espírito, têm um primeiro plano terrível e maldoso" (KSA 8, 3 [17], de 1875, p. 19). Há, no homem, como há na vida e na natureza como um todo, forças impuras, injustas e erradas que servem de "matéria" e de terreno para aquela superação em direção ao além-do-homem. Ao contrário do que propõe, portanto, o trans-humanismo, Nietzsche parte de uma afirmação da natureza própria do homem e, só a partir daí, como um gesto de fidelidade à terra, pode pensar a desejada superação que é, no limite, sempre uma autossuperação, na medida em que parte das forças próprias do indivíduo criador e não de um esforço da civilização, por exemplo, como é o caso da biotecnologia. A direção dessa superação, por isso, não é uma saída da vida, mas uma radical afirmação da natureza própria de cada ser. Para o filósofo alemão, mesmo "o homem mais racional precisa, de tempo em tempo, novamente da natureza, isto é, de sua ilógica relação fundamental com todas as coisas" (HH, 31). Seria preciso, por isso, reconhecer e afirmar a natureza e não fugir dela: "Falamos de natureza e ao fazê-lo nos esquecemos de nós: nós mesmos somos natureza, quand méme [apesar de tudo]. Consequentemente, a natureza é algo inteiramente distinto daquilo que sentimos ao pronunciar seu nome" (AS, 327). Trans-humanistas, nesse sentido, seriam de novo "caluniadores da natureza", ou seja, "pessoas nas quais todo pendor natural se transforma em doença, em algo deformante e ignominioso - elas nos induziram a crer que os pendores e impulsos do ser humano são 
maus; elas são a causa de nossa grande injustiça para com a nossa natureza, para com toda natureza!" (GC, 294). Há pouca "nobreza entre os homens", afirma Nietzsche, justamente onde reina esse comportamento antinatural e, consequentemente, anti-humano e desses processos de melhoramento sempre nascem não homens, mas "homunculus" (KSA 8, 23 [197], de 1876-1877, p. 474), ou seja, um artefato de homem fabricado nos laboratórios daqueles que defendem os velhos valores. Um ser fabricado por feiticeiros, doente e vil, "uma caricatura do homem, um aborto" (CI, "Os 'melhoradores' da humanidade", 2). Essa criatura poderia ser associada ao produto do domínio técnico do mundo, o resultado da "inevitavelmente eminente administração econômica total da terra... aquela maquinaria global, a solidariedade de todas as engrenagens" (KSA 12, 10 [11], de 1887, p. 459). Nesse sentido, como propõe Hauskeller (2016, p. 37), "o além-do-homem não é pensado [por Nietzsche] como um exemplar de um homem futuro ou uma raça pós-humana, mas como um 'homem excepcional' [Ausnahme-Mensch]" e, como tal, alguém que sempre deve ser pensado no singular, ou seja, como resultado de um autocultivo, do crescimento das forças próprias de um espécime cultivado na distância dos modelos gregários.

Ora, a ideia mesma de perfeição, tal como cogitada pelo trans-humanismo, requer uma nova ativação do pensamento gregário pela via da padronização do homem: a perfeição, pensada segundo os velhos valores, segue um mesmo "modelo", projetado em laboratório com vistas à anulação de todo sofrimento e à consolidação de um único ideal de felicidade. Nietzsche, obviamente, não estaria favorável ao fato de seguirmos os valores vigentes (como já vimos anteriormente), muito menos com essa padronização tecnológica ou com essa ideia de felicidade. Quanto a esse terceiro elemento, é bom lembrar que o Übermensch é aquele que, sendo humano, afirma radicalmente todas as "faculdades" ou "propriedades" animais, biológicas e corporais, incluindo a dor e o sofrimento, como parte do jogo de forças que marca a vontade de poder. Nesse sentido, um homem melhor nasceria de um homem mais humano e não o contrário.

\section{Considerações finais}

O lugar ocupado por Nietzsche no trans-humanismo, obviamente, não é consensual. Muito menos seria possível considerar esse um movimento uniforme e simétrico em suas posições. Por medidas didáticas, este artigo não aprofundou a complexidade variável das várias posições identificáveis, nem se deteve na análise dos conceitos de Übermensch e autossuperação do homem 
e não discutiu, ainda, a perspectiva afirmativa ${ }^{12}$ do pensamento de Nietzsche: malgrado isso seria bastante apropriado para a consistência da argumentação, a tarefa excederia em demasiado o adequado tamanho de páginas do presente artigo, de forma que tal tarefa será cumprida em trabalhos posteriores. Almejavase, por isso, tão somente, que a análise aqui proposta levantasse algumas das questões centrais do debate em torno do problema da autossuperação do homem, um conceito que, como vimos, é assimilado pelos trans-humanistas a partir da filosofia nietzschiana.

Nossa posição coteja, como se viu, aquela de Hauskeller e Babich, entre outros, na perspectiva de negar a "dinâmica otimista que caracteriza o pensamento trans-humanista" (Hauskeller, 2016, p. 40) e desvelar a sua face décadent. Nesse sentido, nada poderia ser mais equivocado do que a afirmação de Sorgner (2009, p. 34) de que Nietzsche "estaria a favor da engenharia genética". Ao contrário, ela seria só mais uma expressão da vontade niilista marcada pelo cansaço do homem consigo mesmo e pela vontade de negação que ocorre como fuga da natureza, da vida e do mundo. Além disso, tais tecnologias apoiam-se em uma visão dualista da natureza (de um lado, a natureza orgânico-corporal cujos limites devem ser vencidos; de outro, a natureza racional que se apresenta como essência da humanidade) e, nesse sentido, seguiriam apostando na antropologia platônicocristã denunciada por Nietzsche como uma versão já, em si mesma, moralizada do homem. Nada mais antinietzschiano, portanto, do que a ideia de um homem perfeito, pronto e acabado. Ele não seria mais do que um homúnculo. Como é o caso dos autores existencialistas que o sucederam, também em Nietzsche o homem revela-se na sua ambivalência e na sua indeterminação.

Qualquer coisa que não seja isso não passaria de mais um capítulo da lamentável história metafísica, cujo resultado seria o adoecimento do homem. E nesse sentido, talvez o trans-humanismo possa ser implicado por recorrer novamente ao essencialismo, ao apostar na expansão racional do homem como estratégia central na luta contra as pretensas amarras da natureza. Julian Savulescu (2004, p. 670), entre outros, acredita que a essência do homem reside na sua capacidade racional de autoaperfeiçoamento, o que significa reunir todas as formas para reduzir o homem a um ser controlável. ${ }^{13}$ Mais controlável, o

12 Da qual fazem parte, além dos conceitos de Übermensch e autossuperação, também o amor fati, o eterno retorno, a transvaloração dos valores, a ideia do mundo como fenômeno estético, a vontade de poder e a compreensão da solidão como afirmação de si, entre outros.

13 No seu livro de 2014, Sex and the posthuman condition, Michael Hauskeller destaca e exemplifica como essa tentativa se apresenta nas promessas de melhoramento da performance sexual dos indivíduos humanos, algo que, no fim, o autor identifica como novas formas de uso dos prazeres, pensados a partir de uma ampliação da experiência sexual a tal ponto que o corpo mesmo se torne apenas um "dispositivo masturbatório" enquanto ele não se transforma em algo obsoleto por completo. Sexbots, amantes sintéticos, 
ser humano torna-se, também, cada vez mais manipulável. Onde aumenta o poder também cresce a vulnerabilidade. O niilismo, nesse caso, deixa de ser a crise da esperança, para se tornar, ao contrário, a projeção da perfeição como certeza incontingente. Como Mary Shelley, muitos outros escritores e cineastas vêm advertindo sobre a monstruosidade desse homem perfeito, o moderno Prometeu desacorrentado.

\section{Referências}

BABICH, B. "Friedrich Nietzsche and the Posthuman/Transhuman in Film and Television”. In: M. Hauskeller, T. D. Philbeck, C. Carbonell D. (ed.) The palgrave handbook of posthumanism in film and television. London: Palgrave Macmilan, 2015. pp. 45-53.

. 'Nietzsche's Post-Human Imperative: On the 'All-too-Human' Dream of Transhumanism”. The Agonist, a Nietzsche Circle Journal, Vol. IV, Nr. II, 2011 [Online]. Disponível em: http://goo.gl/U22yVH (Acessado em 10 de janeiro de 2016).

BOSTROM, N. "A History of Transhumanist Thought". Journal of Evolution and Technology, Vol. 14, Nr. 1, 2005 [Online]. Disponível em http://jetpress.org/v20/sorgner. htm (Acessado em 19 de fevereiro de 2016).

HARRIS, J. "Enhancing evolution. The ethical case for making better people". Princeton and Oxford: Princeton University Press, 2007.

HAUSKELLER, M. "Mythologies of Transhumanism". Basingstoke: Palgrave Macmillan, 2016.

. "Sex and the posthuman condition". London: Palgrave Macmillan, 2014.

. "Better humans? Understanding the enhancement project". Durham: Acumen,

2013.

. "Nietzsche, the Overhuman and the Posthuman: A Reply to Stefan Sorgner". Journal of Evolution and Technology, Vol. 21, Nr. 1, January 2010, pp. 5-8 [Online]. Disponível em: http://jetpress.org/hauskeller.htm (Acessado em 18 de fevereiro de 2016). HARRINGTON, Alan. "The Immortalist”. New York: Random House, 1969.

JONAS, H. "O princípio responsabilidade: ensaio de uma ética para a civilização tecnológica". Tradução de Marijane Lisboa, Luiz Barros Montez. Rio de Janeiro: Contraponto: Ed. PUCRio, 2006.

LOEB, P. S. "Nietzsche's Transhumanism". The Agonist, a Nietzsche Circle Journal, Vol. IV, Nr. II, 2011 [Online]. Disponível em: http://goo.gl/U22yVH (Acessado em 10 de janeiro 2016). 
MORE, M. "The Overhuman in the Transhuman". Journal of Evolution and Technology Vol. 21, Nr. 1, pp. 1-4, January 2010 [Online]. Disponível em: http://jetpress.org/v20/ sorgner.htm (Acessado em 10 de fevereiro de 2016).

NIETZSCHE, F. “Humano, Demasiado Humano II". Tradução de Paulo César de Souza. São Paulo: Companhia das Letras, 2008.

. "Assim falou Zaratustra. Um livro para todos e para ninguém”. Tradução de Mário da Silva. Rio de Janeiro: Civilização Brasileira, 2006.

. "A Gaia Ciência". Tradução de Paulo César de Souza. São Paulo: Cia. das Letras, 2002.

. "Crepúsculo dos ídolos (ou como filosofar com o martelo)". $2^{\mathrm{a}}$ ed. Tradução de Marco Antônio Casanova. Rio de Janeiro: Relume Dumará, 2000a. (Conexões, 8). . "Humano, Demasiado Humano. Um livro para espíritos livres". Tradução de Paulo César de Souza. São Paulo: Companhia das Letras, 2000b.

. "Genealogia da Moral. Uma polêmica". Tradução de Paulo César de Souza. São Paulo: Companhia das Letras, 1998.

. "Sämtliche Werke" (KSA). Hg. von G. Colli und M. Montinari. Berlin; New York; München: Walter de Gruyter, 1988.

ONATE, A. M. "Entre eu e si ou a questão do humano na filosofia de Nietzsche". Rio de Janeiro: 7Letras, 2003.

PEARSON, K. A. "The Future is Superhuman: Nietzsche's Gift". The Agonist, a Nietzsche Circle Journal, Vol. IV, Nr. II, 2011 [Online]. Disponível em: http://goo.gl/ U22yVH (Acessado em 30 de janeiro de 2016).

SORGNER, S. "Zarathustra 2.0 and Beyond: Further Remarks on the Complex Relationship between Nietzsche and Transhumanism". The Agonist, a Nietzsche Circle Journal, Vol. IV, Nr. II, 2011 [Online]. Disponível em: http://goo.gl/U22yVH (Acessado em 10 de janeiro de 2016).

. "Nietzsche, the Overhuman, and Transhumanism". Journal of Evolution and Technology, Vol. 20, Nr. 1, pp. 29-42, March 2009 [Online]. Disponível em: http:// jetpress.org/v20/sorgner.htm (Acessado em 18 de fevereiro de 2016).

STOCK, G. "Redesigning Humans: choosing our children's genes". London: Profile, 2002.

TAYLOR, James Stacey. "Practical Autonomy and Bioethics". New York/London: Routledge, 2009. 